\title{
Curiosity and subjective well-being: The mediation of the big five personality traits
}

\author{
Beatrice Adriana Balgiu*, University Politehnica of Bucharest, Splaiul Independentei, 313, 060042 Bucharest, \\ Romania https://orcid.org/0000-0002-4200-2675
}

\section{Suggested Citation:}

Balgiu B. A., (2020). Curiosity and subjective well-being: The mediation of the big five personality traits. Global Journal of Psychology Research: New Trends and Issues. 10(1), 59-67. DOI: 10.18844/gjpr.v\%vi\%i.4458

Received from November 15, 2019; revised from February05, 2020; accepted from March 25, 2020. Selection and peer review under responsibility of Prof. Dr. Tulay Bozkurt, Istanbul Kultur University, Turkey. ${ }^{\circledR} 2020$ Birlesik Dunya Yenilik Arastirma ve Yayincilik Merkezi. All rights reserved.

\begin{abstract}
This study aims to investigate the influence of curiosity on subjective well-being (SWB). More specifically, we examine the mediating role that the Big Five personality traits play in the relationships between these two variables. To this purpose, we used questionnaires in order to measure curiosity (Curiosity and Exploration Inventory-II), SWB (Satisfaction with Life Scale and Scale of Positive and Negative Experiences) and the Big Five personality factors (Big Five Inventory-10) in a case of a sample of 330 undergraduates (Mean age $=18.93$ ). The analysis carried out is based on correlations, regressions and structural equation modelling. The model obtained using structural equation modelling revealed a significant relationship between curiosity and SWB via personality characteristics $\left(\chi^{2} / \mathrm{df}=1.74\right.$; comparative fit index $=0.95$; root mean square error of approximation $=0.051$; standardised root mean square residual $=0.032$ ). Therefore, curiosity correlates significantly with SWB, but individuals characterised by a high degree of curiosity tend to have well-developed well-being since they tend to be extroverted, perseverant and emotionally stable. Future studies should also focus on other types of personality traits.
\end{abstract}

Keywords: Arterial Five personality traits, curiosity, mediation, subjective well-being.

\footnotetext{
* ADDRESS FOR CORRESPONDENCE: Beatrice Adriana Balgiu, University Politehnica of Bucharest, Splaiul Independentei, 313, 060042 Bucharest, Romania. E-mail address: beatricebalgiu@yahoo.com
} 
Balgiu B. A., (2020). Curiosity and subjective well-being: The mediation of the big five personality traits. Global Journal of Psychology Research: New Trends and Issues. 10(1), 59-67. DOI: 10.18844/gjpr.v\%vi\%i.4458

\section{Introduction}

Curiosity first raised researchers' interest in the 1960s and 1970s, when the first substantial studies were carried out (Berlyne, 1960; 1971; Beswick, 1971; Day, 1971; Deci, 1975). However, there are still few empirical studies related to curiosity (Karwowski, 2012).

In their attempt to define curiosity, researchers associated it with the affective state. Thus, curiosity was considered as the desire to eliminate an informational lack when rewards were absent (Golman \& Loewenstein, 2015), the desire resulting from the discrepancy between what we know and what we want to know (Loewenstein, 1994) or as the desire and will to explore the new events, especially when there are situations that have learning potential (Kashdan et al., 2018). Studies show that when we are curious, when we gladly receive the idea that novelty matters more than what we already know, we extract more pleasure and meaning from the world we live in (Jovanovic \& Brdaric, 2012; Kashdan, 2013). More specifically, Kashdan (2013) emphasises that when we question the existing state, when we anticipate the emotion of discovering something or when we live the desired experience, we have positive feelings from the intrinsic reward and we feel excited, enchanted and pleased. To this purpose, in order to cover information, curiosity was conceptualised as either a feeling of interest which appears when the individual experiences the pleasure of discovering something new or a feeling of deprivation due to the pressure stemming from the absence of important and significant information (Litman \& Silvia, 2006).

In their study on the validation of an instrument measuring curiosity (Curiosity and Exploration Inventory-II, CEI-II), Kashdan et al. (2009) defined curiosity as the pursuit of and intense wish to explore new and uncertain events. The essence of curiosity entails a high degree of receptivity and the will to engage in new stimuli. This includes the interest in new things, a receptive attitude and openness to whatever represents the target of one's attention. The authors refined this definition of curiosity by establishing two of its components: stretching - the active exploration of new information and experiences; and embracing - the will to embrace new and unpredictable situations in day-to-day life (Kashdan et al., 2009; 2018).

One of the most analysed correlates of curiosity is well-being (Jovanovic \& Brdaric, 2012; Kashdan \& Steger, 2007; Kashdan et al., 2009; 2018; Wang \& Li, 2015). For example, Kashdan et al. (2009) demonstrated the relationship between curiosity and its subcomponents (stretching and embracing) and all three forms of well-being: subjective (positive affectivity and happiness), psychological (measured after the model of Ryff \& Singer, 1998) and, primarily, social (measured by the Mental health continuum (MHC) scale developed by Keyes in 1998).

Most studies on curiosity agree with one another in this respect. Gallagher and Lopez (2007) describe people with high degrees of curiosity as being generally characterised by a higher degree of happiness and positive affectivity. Kashdan et al. (2009) found a close relationship between curiosity and the dimensions of psychological well-being, such as autonomy, personal development, selfacceptance and purpose in life. When they discussed the criteria for a strong character, Park, Peterson and Seligman (2004) showed that curiosity is substantially related to life satisfaction. Fredrickson (2019) emphasises that positive emotions awaken the impulse to explore and learn, making us more receptive and creative.

Kashdan and Steger (2007) tested whether trait curiosity and daily curiosity led to greater sustainable well-being using two models of well-being (eudaimonic and hedonic). The authors found that on days when people are more curious, those high in curiosity reported more frequent growthoriented behaviours and a greater presence of meaning, search for meaning and life satisfaction. Greater trait curiosity and greater curiosity on a given day also predict greater persistence of meaning in life from one day to the next. People with greater trait curiosity have more frequent hedonistic events but these are associated with less pleasure compared with the experiences of people with less trait curiosity. The studies carried out in the organisational environment empirically show the influence of curiosity on the increase of psychological well-being and on the decrease of professional 
burnout (Wang \& Li, 2015). It is considered that employees with great curiosity are more likely to experience positive emotions or subjective feelings (Leonard \& Harvey, 2007). However, other studies consider that only stretching predicts the positive affect, while embracin \& Gavrilov-Jerkovic, 2014). Similarly, research on students demonstrates that both stretching and embracing correlate with wellbeing, but only stretching is a predictor of positive affect and of flourishing (Miljkovic \& Jurcec, 2016). As for the relationship between curiosity and the Big Five personality characteristics (extraversion, agreeableness, conscientiousness, neuroticism and openness to experience), the research highlighted the association between curiosity and most of the Big Five factors. In a study on 294 Chinese students, Ye, Ng, Yim and Wang (2015) found positive correlations between curiosity and extraversion, agreeableness, conscientiousness, openness to experience and openness to change in values, and negative correlations with neuroticism. Kashdan et al. (2009) found positive correlations between the total score of curiosity and extraversion $(r=0.42)$, openness to experience $(r=0.51)$ and conscientiousness $(r=0.20)$, and negative correlations with neuroticism ( $r=-0.27)$. The analysis of the theoretical framework of the Big Five reveals that curiosity is a central facet of openness to experience (Caprara, Barbaranelli \& Borgogni, 1993; Minulescu, 2008), or it is seen as a sub-trait of the latter (McCrae, 1987).

On the other hand, positive correlations with extraversion and negative correlations with neuroticism obtained in research (Kashdan et al., 2009; 2018; Kashdan, Afram, Brown, Birnbeck \& Drvoshanov, 2011) suggest that curiosity can also be positively associated with the meta-trait plasticity, a factor combining openness to experience and extraversion (DeYoung \& Peterson, 2008).

This study aims to investigate the role of personality traits within the mechanism by which curiosity influences students' well-being. Taking into consideration the previous literature, we hypothesise that:

1. Curiosity is positively related to personality traits;

2. Curiosity predicts SWB;

3. Personality traits are related to SWB;

4. Personality traits mediate the relationship between curiosity and SWB.

\section{Method}

\subsection{Participants and procedure}

The data for this study come from undergraduate students from a large technical public university $\left(N=330 ; M_{\text {age }}=18.93 ;\right.$ SD. $=0.66 ; 148$ male and 182 female with no significant age differences). The students were randomly selected from the years I and II of study, in academic years 2016-2017 and 2017-2018, and the administration of the instruments was conducted during didactic activities. The instruments were administered in groups and each administration was completed in about 15 minutes. The students were informed of the confidentiality of the results and did not receive the reward for completing the set of measures.

The data of this study were collected through the following measures:

1. Curiosity and Exploration Inventory-II (CEI-II)contains 10 items assessed on a scale from 1 - very little or not at all to 5 - to the highest extent, and it is structured around two subscales: stretching or exploration - the motivation to look for knowledge and new experiences (e.g. 'I am at my best when doing something that is complex or challenging') and embracing - the willingness to embrace newness, uncertainty and the unpredictable nature of day-to-day life (e.g. I like to do things that are a little frightening) (Kashdan et al., 2009). The sum of the scores for the two scales is the score for curiosity. The Cronbach's alpha indexes reported by the authors in the three studies on the inventory validation vary from 0.78 to 0.80 for stretching, from 0.83 to 0.85 for embracing and from 0.83 to 0.85 for the total score of the two subscales of the total CEI (Kashdan et al., 2009). In the present research, we found $\alpha=0.70$ for the stretching subscale and $\alpha=0.79$ for the embracing subscale and 
Balgiu B. A., (2020). Curiosity and subjective well-being: The mediation of the big five personality traits. Global Journal of Psychology Research: New Trends and Issues. 10(1), 59-67. DOI: 10.18844/gjpr.v\%vi\%i.4458

well goodness-of-fit: $\chi^{2} / \mathrm{df}=2.26$; comparative fit index $(\mathrm{CFI})=0.93$; root mean square error of approximation $(R M S E A)=0.060$; standardised root mean square residual $(S R M R)=0.049$.

2. Satisfaction with Life Scale (SWLS) takes into account cognitive assessment of life satisfaction (Diener, Emmons, Larsen \&Griffin, 1985). The SWLS is a short 5-item instrument designed to measure global cognitive judgements of satisfaction with one's life (for example, 'In most ways, my life is close to my ideal').Scores on the SWLS have been shown to correlate with measures of mental health and be predictive of future behaviours, such as suicide attempts. The SWLS is a 7-point Likert style response scale $(\alpha=0.79-0.89 ;$ Pavot $\&$ Diener, 1993). The scale, also, showed high internal consistency in the present study $(\alpha=0.80)$ and excellent fit: $\chi^{2} / d f=2.20 ; C F I=0.95 ;$ RMSEA $=0.049$; SRMR $=0.015$.

3. Scale of Positive and Negative Experience (SPANE) assesses a broad range of pleasant and unpleasant feelings by asking people to report their feelings in terms of their duration after recalling their activities and experiences during the previous four weeks (Diener et al., 2010).SPANE consists of 12 items: six items assess positive feelings (SPANE-P) and the other six assess negative feelings (SPANE-N) on a scale of 1 - very rarely or never to 5 - very often or always. Finally, the affect balance is also calculated (SPANE-B): the negative feelings score is subtracted from the positive feelings score. Cronbach's alpha varies between 0.81 and 0.89 (Diener et al. 2010). In the present study, Cronbach's alpha indices were 0.85 (SPANE-P), 0.83 (SPANE-N) and $\chi^{2} / \mathrm{df}=2.80 ; \mathrm{CFI}=0.95 ; \mathrm{RMSEA}=0.060 ; \mathrm{SRMR}=0.047$.

4. Big Five Inventory-10(BFI-10)measures the personality factors (extraversion, agreeableness, conscientiousness, neuroticism and openness to experience) within the Model Big Five on a scale of 1 - strongly disagree to 5 - strongly agree(Rammstedt \& John, 2007). The questionnaire contains 10 items, of which five are quantified in reverse. The authors standardised the questionnaire by using four US and German cross-cultural samples, and the scales of BFI retain significant levels of validity and fidelity. Results of the test-retest are $\alpha=0.72$ (US sample) and 0.78 (German sample) (Rammstedt \& John, 2007). In the present piece of research, the consistency indexes varied from $\alpha=0.30$ for agreeableness and openness, to $\alpha=0.38$ for extraversion, $\alpha=0.40$ for neuroticism and $\alpha=0.60$ for conscientiousness. Given that the minimum permitted for extra-short scales with two items per factor is 0.45 , one can consider that the indexes are acceptable, except for agreeableness and openness, which have the lowest index (Thalmayer, Saucier \& Eigenhuis, 2011). The 5-factor solution presents the next goodness-of-fit: $\chi^{2} / d f=2.80 ; \mathrm{CFI}=0.92 ; \mathrm{RMSEA}=0.060 ; \mathrm{SRMR}=0.050$.

\subsection{Statistical strategies}

First, correlational and regression analysis was examined. Next, structural equation modelling (SEM) was used to explore the relationships between curiosity, personality traits and well-being and the estimation of the model based on gender differences. In this framework, the following indicators were used: $\chi^{2}$ value, degree of freedom (df), CMIN (minimum discrepancy divided by its degree of freedom), goodness-of-fit (GFlindex), adjusted goodness-of-fit (AGFlindex), incremental fit index (IFI), CFI, RMSEA and SRMR. According to Finney and DiStefano (1999), the fit indexes are well if CFI,GFI, AGFI and IFI are $\geq 0.95$, RMSEA is above 0.06 and SRMR is above0.080. The collected data were analysed with SPSS V22 and AMOS 20 (IBM, New York, NY).

\section{Results}

In order to analyse the relationship between curiosity and well-being, we built a composite measure named SWB index by standardising SWLS and SPANE and their combination. Thus, SWB index $=$ life satisfaction + (positive affect - negative affect); in these conditions, the two dimensions of wellbeing, the affective and the cognitive, are incorporated into a new measure. We also put forth the Pearson's correlations between the mentioned variables: positive affect and negative affect $(r=-0.34$; $p<0.01)$; life satisfaction and positive affect $(r=0.36 ; p<0.01)$; and life satisfaction and negative affect $(r=-0.23 ; p<0.01)$. Since a prerequisite of mediation is that the predictor, the dependent variable and 
the potential mediators should have significant bi-varied correlations, we initially resorted to correlation analysis.

The correlations between SWB, its components and curiosity are shown in Table 1 . Thus, curiosity makes moderate positive correlations with positive affect $(r=0.26 ; p<0.01)$, with life satisfaction $(r=0.23 ; p<0.01)$ and with the total SWB score $(r=0.23 ; p<0.01)$.

Table 1.Correlations between curiosity and subjective well-being

\begin{tabular}{lcccc}
\hline \multicolumn{1}{c}{ Variables } & PA & NA & LS & SWB index \\
\hline Stretching & $0.25^{* *}$ & -0.01 & $0.22^{* *}$ & $0.21^{* *}$ \\
Embracing & $0.21^{* *}$ & -0.03 & $0.19^{* *}$ & $0.20^{* *}$ \\
Curiosity & $0.26^{* *}$ & -0.02 & $0.23^{* *}$ & $0.23^{* *}$ \\
\hline
\end{tabular}

$* * p<0.01$.

$P A=$ positive affect; NA =negative affect; LS =life satisfaction;

SWB =subjective well-being.

Table 2 highlights the correlations between curiosity and personality traits. Thus, curiosity is associated with all five personality factors (extraversion, agreeableness, conscientiousness, neuroticism and openness to experience). The strongest correlations are made with extraversion and openness to experience $(r=0.29$ and 0.24 , respectively; $p<0.01)$ and the weakest with agreeableness $(r=0.12 ; p<0.05)$.

Table 2.Correlations between curiosity and Big Five personality traits

\begin{tabular}{lccccc}
\hline \multicolumn{1}{c}{ Variables } & Extraversion & Agreeableness & Conscientiousness & Neuroticism & Openness \\
\hline Stretching & $0.16^{* *}$ & $0.14^{*}$ & $0.24^{* *}$ & $-0.20^{* *}$ & $0.23^{* *}$ \\
Embracing & $0.32^{* *}$ & 0.07 & 0.12 & $-0.17^{* *}$ & $0.22^{* *}$ \\
Curiosity & $0.29^{* *}$ & $0.12^{*}$ & $0.20^{* *}$ & $-0.19^{* *}$ & $0.24^{* *}$ \\
\hline
\end{tabular}

Table 3 shows the correlations between the Big Five characteristics and positive affect (PA) and negative affect (NA), as well as life satisfaction (LS) and the SWB index. One can note that SWB makes moderate positive associations with extraversion and conscientiousness $(r=0.29$ and $0.27 ; p<0.01)$, weak associations with agreeableness $(r=0.18 ; p<0.01)$ and negative associations with neuroticism $(r=0.34 ; p<0.01)$.

Table 3. Correlations between Big Five personality traits and subjective well-being

\begin{tabular}{lccccc}
\hline Variables & Extraversion & Agreeableness & Conscientiousness & Neuroticism & Openness \\
\hline PA & $0.23^{* *}$ & $0.12^{*}$ & $0.18^{* *}$ & $-0.13^{*}$ & 0.10 \\
NA & $-0.18^{* *}$ & $-0.17^{* *}$ & $-0.14^{*}$ & $0.33^{* *}$ & 0.01 \\
LS & $0.25^{* *}$ & $0.11^{*}$ & $0.26^{* *}$ & $-0.27^{* *}$ & 0.03 \\
SWB & $0.29^{* *}$ & $0.18^{* *}$ & $0.27^{* *}$ & $-0.34^{* *}$ & 0.03 \\
\hline
\end{tabular}

$* * p<0.01 ; * p<0.05$.

PA =positive affect; NA =negative affect; LS =Life satisfaction; SWB =Subjective well-being

Also, as a preliminary analysis, the regression between curiosity and the SWB index (the c path) is calculated by observing first that the conditions for applying the regression are met: the dependent variable and the errors are normally distributed and the Cook's distance shows that there are no influential cases in the sample (0.000-0.163).

Table 4. Results of stepwise linear regressions between curiosity and subjective well-being

\begin{tabular}{ccccccccc}
\hline Model & $\boldsymbol{R}$ & Adjusted $\boldsymbol{R}^{\mathbf{2}}$ & Standard error & $\boldsymbol{B}$ & $\boldsymbol{t}$ & Sig. & $\boldsymbol{F}$ & Sig. \\
\hline Curiosity & 0.23 & 0.05 & 9.88 & 0.230 & 4.02 & 0.000 & 16.174 & 0.000 \\
\hline
\end{tabular}

a. Dependent variable: curiosity; b. Predictor: SWB index 
Balgiu B. A., (2020). Curiosity and subjective well-being: The mediation of the big five personality traits. Global Journal of Psychology Research: New Trends and Issues. 10(1), 59-67. DOI: 10.18844/gjpr.v\%vi\%i.4458

Testing is conducted by also observing the skewness and kurtosis values. The result of the regression analysis shows that curiosity explains $23 \%$ of the SWB variance, thus confirming the hypothesis that curiosity predicts SWB (Table 4).

We continued with the method which is certain to determine the effects of the mediation, namely the bootstrap method (Hadi, Abdullah \& Sentosa, 2016), a consistent method for obtaining robust statistics in SEM (Finney \& DiStefano, 2013). In order to verify the obtained result, we proposed a mediation model using the bootstrapping method on 2000 bootstrap samples by using AMOS.

The relationships predicted by the model were tested by using path analysis with normal theory of generalised least squares. The adequacy of the model was verified by means of the absolute indexes: $\chi^{2}, \mathrm{df}, \mathrm{CMIN}, \mathrm{GFI}, \mathrm{AGFI}$, IFI, CFI, RMSEA and SRMR.

In order to determine the statistical significance of the proposed theoretical model, the following criteria were proposed: a) $\chi^{2}$ test should be insignificant from a statistical point of view; and b) the statistical significance of every parameter should be estimated for paths in the model. As shown in Table 5, the non-significant chi-square suggests that the model fits the sample data $(p=0.122)$. The analysis of the indexes in Table 5 tests the adequacy of the model.

Table 5.Summary of the fit indices for model

\begin{tabular}{cccccccccc}
\hline Model & $\chi^{\mathbf{2}}$ & df & CMIN/df & GFI & AGFI & IFI & CFI & RMSEA & SRMR \\
\hline Default model & 8.70 & 5 & 1,74 & 0.991 & 0.959 & 0.958 & 0.952 & 0.051 & 0.032 \\
\hline
\end{tabular}

Thus, $\chi^{2}=8.70$ and $\mathrm{df}=5 ; \chi^{2} / \mathrm{df}=1.74$; consequently <2.Indicators $\mathrm{GFI}, \mathrm{AGFI}, \mathrm{IFI}$ and $\mathrm{CFI}$ reached values over 0.95, RMSEA has a value of 0.051 [Confidence Interval $(\mathrm{Cl}) 90 \%=0.000-0.104$ ] and $\mathrm{SRMR}=$ 0.032 . The standardised coefficients shown in Figure 1 emphasise that the SWB index is predicted by extraversion $(B=0.23)$, conscientiousness $(B=0.21)$ and neuroticism $(B=-0.25)$.

The effect of openness to experience on SWB is not significant $(B=-0.01)$. The standardised indirect (mediated) effect of curiosity on SWB was statistically significant $(\theta=0.15 ; p=0.001)$. The standardised indirect (mediated) effect is significantly different from zero ( $p=0.001$, two-tailed significance).

Using the bootstrap approximation, the two-sided, bias-corrected $\mathrm{Cl}$ obtained was 0.162-0.353. Because this interval did not include the value 0 , it could be asserted that the indirect effect of curiosity on SWB is statistically significant. The direct effect of curiosity on SWB (the $c^{\prime}$ path) is 0.08 $(p=0.170)$ and is insignificant. As shown in the classic article by Baron and Kenny (1986), if $c^{\prime}$ is closer to zero than $\mathrm{C}$, and non-significant, it is legitimate to conclude that the mediators completely mediate the association between curiosity and SWB.

\section{Discussion, conclusion and recommendations}

Studies have shown that both curiosity and personality are significantly related to SWB (Jovanovic \& Brdaric, 2012; Kashdan \& Steger, 2007; Kashdan et al., 2018). The results of this research show that curiosity predicts SWB if it is accompanied by particular traits.

According to the model obtained, extraversion, conscientiousness and (negatively) neuroticism have a mediating role in the relationships between curiosity and SWB. Therefore, the results of the study lead to the suggestion that curiosity predicts SWB only to the extent to which it is accompanied by other particular traits. Individuals characterised by a high degree of curiosity tend to have a welldeveloped well-being since they tend to be extraverted, perseverant, responsible and emotionally stable. Consistent with prior studies, curiosity and the Big Five personality factors are associated with well-being (Kashdan et al., 2009; Ye et al., 2015). However, the association between curiosity and SWB seems to be the result of the variance that both shares with the personality traits. 


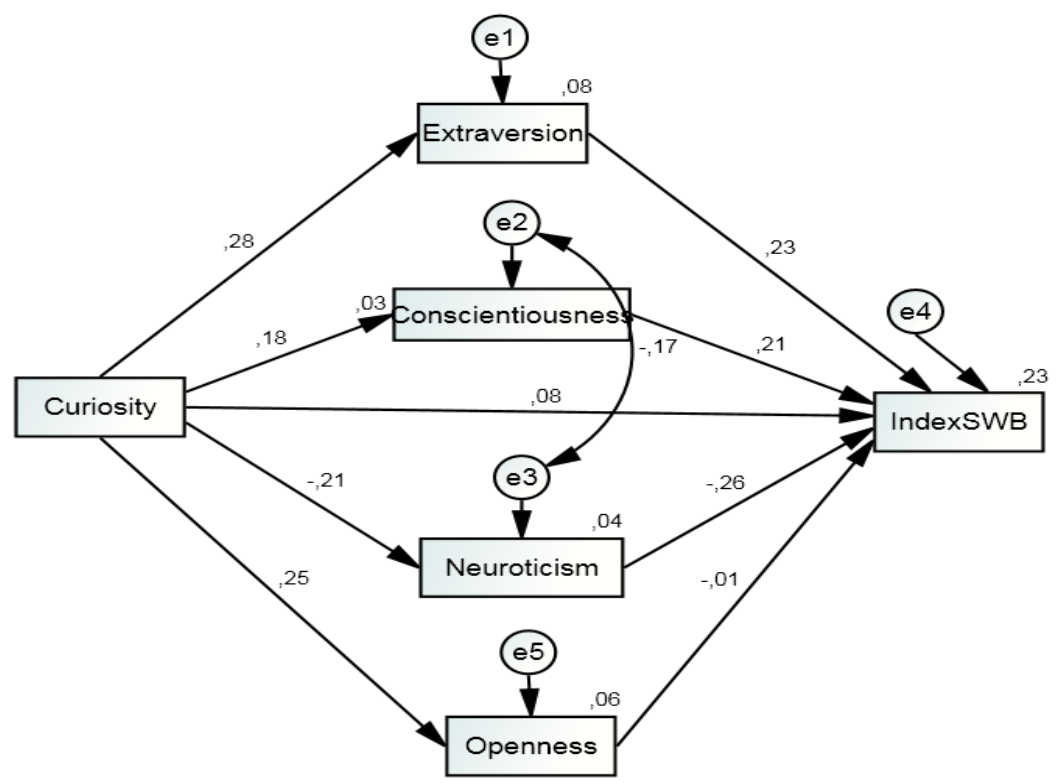

Figure 1. Structural equation model of how curiosity influences subjective well-being

For example, people of high curiosity tend to have high SWB because they tend to be extroverted. Therefore, the students analysed experience a state of well-being due to their curiosity in the conditions in which they are extroverted, conscientious and emotionally balanced. It is well-known that extroverted people manage to cope with uncertainty better due to traits such as flexibility, selfconfidence and creativity (Minulescu, 2008). Similarly, people with a high degree of conscientiousness and emotional stability have more developed will, carefully control their energy in order to cope with difficulties and make the effort to keep finding out and acting (Caprara et al., 1993; McCrae \& Costa, 2003; Minulescu, 2008). Therefore, curiosity influences SWB but it has an indirect association with SWB through interactions with other psychological variables, in this case, the specific Big Five traits of extraversion, conscientiousness and emotional stability. Also, in other cases, the influence of curiosity can be seen on well-being (psychological well-being) through other psychosocial variables, such as personal initiative (Wang \& Li, 2015).As most Big Five personality models reveal, the openness factor includes curiosity in its content. However, in the case of the studied group, it seems that openness does not mediate the relationship between curiosity and SWB. This may be because openness does not have a very high level in the case of the analysed group. Its role should be analysed in further studies.

Among the study limits, we note that beside the sample size, the character of the instruments used, the fact that short scales with five items, the shortest scale (SWLS) up to 12 items (SPANE), were used. Moreover, BFI-10 is a scale with many problems, the most important one being low fidelity in the case of agreeableness and conscientiousness (Carciofo, Yang, Song, Du\& Zhang, 2016; Pejic, Tenjovic \& Knezevic, 2014). This is the reason we claim the investigation of the relationship between personality, well-being and curiosity and with more complex measures, but also with the introduction of variables constituted in possible mediators or moderators of the relationship under consideration.

The relationship between curiosity and SWB appears in many studies, but we consider that the present study is the first to demonstrate the mediating role of personality traits in association with two variables. It is not the only characteristics of the Big Five model that can mediate the relationship between curiosity and well-being. It is important to evaluate other personality traits in relation to curiosity and psychosocial well-being. People with epistemic curiosity (as opposed to dark curiosity) are also visionary, perfectionist, creative, flexible, proactive, meaningful and tolerant of uncertainty. It is expected that further research will consider investigating these associations between curiosity, 
Balgiu B. A., (2020). Curiosity and subjective well-being: The mediation of the big five personality traits. Global Journal of

Psychology Research: New Trends and Issues. 10(1), 59-67. DOI: 10.18844/gjpr.v\%vi\%i.4458

personal characteristics and well-being. In future studies, it is necessary to examine curiosity in relation to other personality traits to see what other characteristics are associated with curiosity and SWB. This may also show if personality traits are associated with high levels of curiosity. The study's findings may have practical implications for personnel selection. The professional selection of people in different jobs is made in most cases based on personality traits. We could know that if we select individuals with certain personality traits, high degrees of curiosity also occur in their characterisation.

\section{Acknowledgement}

The authors are grateful to all the students who participated in this study.

\section{References}

Baron, R. M. \& Kenny, D. A. (1986). The moderator-mediator variable distinction in social psychological research: Conceptual, strategic, and statistical considerations. Journal of Personality and Social Psychology, 51, $1173-1182$.

Berlyne, D. E. (1960). Conflict, arousal, and curiosity. New York: McGraw-Hill.

Berlyne, D. E. (1971). Aesthetics and psychobiology. New York: Appleton-Century Crofts.

Beswick, D. G. (1971). Cognitive process theory of individual differences in curiosity. In H. I. Day, D. E. Berlyne \& D. E. Hunt (Eds.), Intrinsic motivation: a new direction in education (pp. 156-170). New York: Holt, Rinehart \& Winston.

Caprara, G.V., Barbaranelli, C. \& Borgogni, L. (1993). BFQ: Big Five questionnaire, manuale. Firenze, Italy: Organizzazioni Speciali.

Carciofo, R., Yang, J., Song, N., Du, F. \& Zhang, K. (2016). Psychometric evaluation of Chinese-language 44-item and 10-item Big Five Personality Inventories, including correlations with chronotype, mindfulness and mind wandering, PLoS One, 11(2), e0149963.

Day, H. I. (1971). The measurement of specific curiosity. In H. I. Day, D. E. Berlyne \& D. E. Hunt (Eds.), Intrinsic motivation: a new direction in education (pp.99-112). New York: Holt, Rinehart, \& Winston.

Deci, E. (1975). Intrinsic motivation. New York: Plenum.

Diener, E., Emmons, R.A., Larsen, R.J. \& Griffin, S. (1985). The satisfaction with life scale. Journal of Personality Assessment, 49(1), 71-75.

Diener, E., Wirtz, D., Tov, W., Kim-Prieto, C., Choi, D., Oishi, S. \& Biswas-Diener, R. (2010). New measures wellbeing: flourishing and positive and negative feelings. Social Indicator Research, 39, 247-266.

DeYoung, C. G., Peterson, J. B., Séguin, J. R.\& Tremblay, R. E. (2008). Externalizing behavior and the higher order factors of the Big Five. Journal of Abnormal Psychology, 117(4), 947-953.

Finney, S.J.\& DiStefano, C. (2013). Non-normal and categorical data in structural equation modeling. In G.R. Hancock \& R.O. Mueller (Eds.), Structural equation modeling. A second course (2nd ed.) (pp. 439-492), Charlotte: Information Age Publishing.

Fredrickson, B.L. (2019). Puterea emoţiilor pozitive [Positivity]. Bucuresti, Romania: Editura Litera.

Gallagher, M. W. \& Lopez, S. J. (2007). Curiosity and well-being. Journal of Positive Psychology, 2(4), 236-248.

Golman, R. \& Loewenstein, G. (2015). Curiosity, information gaps, and the utility of knowledge. Retrieved from: http://ssrn.com/abstract=2149362

Hadi, N.U., Abdullah, N. \& Sentosa, I. (2016). Making sense of mediating analysis: A marketing perspective. Review of Integrative Business \& Economics Research, 5(2), 62-76.

Jovanovic, V., \& Brdaric, D. (2012). Did curiosity kill the cat? Evidence from subjective well-being in adolescents. Personality and Individual Differences, 52(3), 380-384.

Jovanovic, V. \& Gavrilov-Jerkovic, V. (2014). The good, the bad (and the ugly): the role of curiosity in subjective well-being and risky behaviors among adolescents. Scandinavian Journal of Psychology, 55(1), 38-44.

Karwowski, M. (2012). Did curiosity kill the cat? Relationship between trait curiosity, creative self-efficacy and creative personal identity. Europe's Journal of Psychology, 8, 547-558. 
Balgiu B. A., (2020). Curiosity and subjective well-being: The mediation of the big five personality traits. Global Journal of

Psychology Research: New Trends and Issues. 10(1), 59-67. DOI: 10.18844/gjpr.v\%vi\%i.4458

Kashdan, T. B. \& Steger, M. F. (2007). Curiosity and pathways to well-being and meaning in life: Traits, states, and everyday behaviors. Motivation and Emotion, 31(3), 159-173.

Kashdan, T.B., Gallagher, M.W., Silvia, P.J., Winterstein, B.P., Breen, W.E., Terhar, D. \& Steger, M.F. (2009). The curiosity and exploration inventory-II: development, factor structure, and initial psychometrics. Journal of Research in Personality, 43(6), 987-998.

Kashdan, T. B., Afram, A., Brown, K. W., Birnbeck, M. \& Dr voshanov, M. (2011). Curiosity enhances the role of mindfulness in reducing defensive responses to existential threat. Personality and Individual Differences, 50, 1227-1232.

Kashdan, T, B. (2013). Curios?: Descopera ingredientul care-ti lipseşte pentru o viataimplinita [Curious?: Discover the missing ingredient to a fulfilling life]. Bucuresti, Romania: Editura Trei.

Kashdan, T.B., Stiksma, M.C., Disabato, D.J., McKnight, P.E. Bekier, J., Kaji, J. \& Lazarus, R. (2018). The five dimensional curiosity scale: capturing the bandwidth of curiosity and identifying four unique subgroups of curious people. Journal of Research in Personality, 73, 130-149.

Keyes, C.L.M. (1998). Social well-being. Social Psychology Quarterly, 61(2), 121-140.

Leonard, N.H. \& Harvey, M. (2007). The trait of curiosity as a predictor of emotional intelligence. Journal of Applied Social Psychology, 37(8), 1914-1929.

Litman, J. A. \& Silvia, P. J. (2006). The latent structure of trait curiosity: evidence for interest and deprivation curiosity dimensions. Journal of Personality Assessment, 86(3), 318-328.

Loewenstein, G. (1994). The psychology of curiosity: a review and reinterpretation. Psychological Bulletin, 116, 75-98.

McCrae, R. R. (1987). Creativity, divergent thinking, and openness to experience. Journal of Personality and Social Psychology, 52(6), 1258-1265.

McCrae, R. R. \& Costa, P. T. (2003).Personality in adulthood: a five-factor theory perspective (2nd ed.). New York: Guilford Press.

Miljkovic, D. \& Jurcec, L. (2016). Is curiosity good for students' well-being? The case of the Faculty of Teacher Education and the Faculty of Kinesiology. Croatian Journal of Education, 18(1), 103-121.

Minulescu, M. (2008) $A B C D-M$, Manual tehnic si interpretativ [ $A B C D-M$, Technical and interpretative manual]. Cluj-Napoca, Romania: Editura Sinapsis.

Pavot, W. \& Diener, E., (1993). Review of the satisfaction with life scale. Psychological Assessment, 5(2), 164-172.

Park, N., Peterson, C. \& Seligman, M.E.P. (2004). Strengths of character and well-being. Journal of Social and Clinical Psychology, 23(5), 603-619.

Pejic, M., Tenjovic, L. \& Knezevic, G. (2014). Validation of the BFI-10 questionnaire - short version of the big five inventory. Applied Psychology, 7(1), 45-92.

Rammstedt, B. \& John, O.P. (2007). Measuring personality in one minute or less: a 10-item short version of the Big Five Inventory in English and German. Journal of Research in Personality, 41(1), 203-212.

Ryff, C.D. \& Singer, B. (1998). The contours of positive human health. Psychological Inquiry, 9(1), 1-28.

Steel, P., Schmidt, J. \& Schultz, J. (2008). Refining the relationship between personality and subjective well-being. Psychological Bulletin, 134(1), 138-161.

Thalmayer, A.G., Saucier, G. \& Eigenhuis, A. (2011) Comparative validity of brief to medium-length Big Five and Big Six Personality Questionnaires. Psychological Assessment, 23(4), 995-1009.

Wang, H. \& Li, J. (2015). How trait curiosity influences psychological well-being and emotional exhaustion: the mediating role of personal initiative. Personality and Individual Differences, 75, 135-140.

Ye, S., Ng, T.K., Yim, K.H. \& Wang, J. (2015). Validation of the curiosity and exploration inventory-II (CEI-II) among Chinese university students in Hong Kong. Journal of Personality Assessment, 97(4), 403-410. 